\title{
Consumers' sensory and nutritional perceptions of three types of milk
}

\author{
AEM Bus ${ }^{1,2}$ and A Worsley ${ }^{1, *}$ \\ 'School of Health Sciences, Deakin University, 221 Burwood Highway, Burwood, Victoria 3125, Australia: \\ ${ }^{2}$ Division of Human Nutrition and Epidemiology, Wageningen University, Dreyenlaan 1, 6703 HA Wageningen, \\ The Netherlands
}

Submitted 24 June 2002: Accepted 10 September 2002

\begin{abstract}
Objective: To identify consumer perceptions of whole milk, reduced-fat milk and soy milk, and to investigate demographic influences on perceptions and types of milk consumption.

Design and setting: Questionnaires covering nutritional and sensory perceptions of three types of milk.

Subjects: Three hundred and sixty-one randomly selected shoppers in Melbourne, Australia.

Results: Generally, respondents held positive perceptions about milk. Milk was considered as having good sensory properties, providing a good source of nutrients, and being a convenient and safe product. However, despite these findings, misperceptions and unawareness about the nutrient content of milk were prevalent. Negative perceptions were most common for whole milk and were mostly related to its perceived high fat, cholesterol and energy contents. Soy milk received lower ratings on sensory quality and convenience than dairy milk. There were few sociodemographic differences in consumers' perceptions. Although reduced-fat milk consumption was more frequent among elderly people and type of milk consumption was related to parenthood, no other significant effects of demographic variables were found on the consumption of specific milk types.

Conclusion: Although positive perceptions were common, negative perceptions and misperceptions appear to be prevalent, presenting a challenge for nutrition education. Sociodemographic factors were not shown to be important predictors of perceptions and type of milk consumption.
\end{abstract}

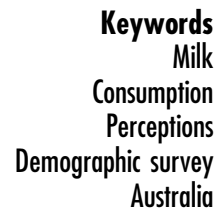

Milk is an important food component in Western countries. From a nutritional point of view, milk is an important source of protein, vitamins and minerals. In particular, cow's milk is the major source of dietary calcium, providing 69\% of calcium intake in Australia ${ }^{1}$.

Adequate calcium consumption is essential for optimal bone density, and is thus an important factor in the prevention of osteoporosis ${ }^{2}$. Recent clinical and biochemical research has indicated that consumption of (lowfat) milk (products) may also be associated with reduced risks of hypertension, dental caries, colon cancer, heart disease and stroke $\mathrm{e}^{2-5}$. Research has shown that the general public is usually aware of the importance of milk and milk products, particularly that milk is a good source of calcium and that it is important for bone health ${ }^{6-11}$. However, despite this knowledge, calcium intake is often not adequate in the Australian population ${ }^{12}$. It may be that consumers hold negative beliefs about the sensory and nutritional properties of milk that outweigh any positive perceptions.
Previous work revealed that perceptions such as perceived sensory properties ${ }^{7-11,13-17}, \operatorname{cost}^{8,10,11,14}$, convenience $^{8,10}$, familiarity/habit ${ }^{13,16,17}$, nutritional knowledge and beliefs ${ }^{8,14,18}$, and concerns about fat and cholesterol contents $7,8,10,11,14,15,17-19$ all influence milk consumption and attitudes towards the different types of milk.

Taste is a major determinant of food choice. Wham ${ }^{11}$ found that the majority of respondents $(>73 \%)$ had positive attitudes towards the taste of milk, but no distinctions between types of milk were made. However, previous studies have shown that taste perceptions of milk are influenced by the fat content ${ }^{17,20}$. For example, Brewer et $a l .{ }^{17}$ found that subjects preferred whole milk to skimmed milk, and that the sensory score for liking increased with increasing fat content. Richardson-Harman et $a .^{20}$ also found a positive relationship between creaminess and preference, with products higher in fat being perceived as creamiest. Therefore, it is hypothesised that consumers will have more positive views about 
the sensory quality of whole milk compared with reducedfat milk.

Taste, however, might not be the major determinant of type of milk consumption. Previous studies have indicated that, rather than taste, beliefs about the health and nutritional benefits may be more important predictors of low-fat milk consumption ${ }^{13,17,18}$.

Since reduced-fat milk and whole milk differ substantially only in fat content, it would be expected that differences in perceptions between milks relate to the fat content. More positive taste perceptions and more negative perceptions of the energy, fat and cholesterol contents would be expected for whole milk compared with reduced-fat milk. However, it is not known whether perceptual differences relate only to the fat content or whether other perceptions are affected as well.

Soy 'milk' is growing in popularity and it is being marketed aggressively as a light alternative to milk, although most soy beverages contain similar amounts of fat as whole cow's milk. Although soy 'milk' has different nutritional properties, it is marketed as though it were a milk product possessing similar nutritional properties. Despite this marketing, however, little is known about consumer perceptions of soy milk.

Demographic differences in perceptions have been reported in previous studies. Since women are more concerned with reduction of dietary fat intake and body weight $^{11,21,22}$ and higher socio-economic status (SES) is positively correlated with healthy dietary patterns ${ }^{23,24}$, differences in fat-related perceptions and interactions between types of milk and demographics would be expected across demographic groups. In addition, Wham ${ }^{11}$ found that women generally held more positive beliefs about the taste, health, nutrition and price of milk than did men and that people of high occupational status were more concerned about cholesterol. Misperceptions and uncertainty about the nutrient content of milk may also be prevalent. A survey in New Zealand ${ }^{11}$ found that $49 \%$ of the respondents agreed that milk is a good source of iron and that agreement was higher among lesseducated people. Since previous research ${ }^{8}$ found a positive correlation between educational level and nutritional knowledge, we expected that people with higher educational levels would hold more correct perceptions.

In addition to influencing perceptions, sociodemographic variables such as sex, age, education, SES and ethnicity also influence the actual type of milk consumption. Various studies have revealed that low-fat milk consumption is more frequent among women and is positively related to age and SES, whereas the opposite pattern is seen with whole milk ${ }^{19,24,25}$.

The present study focused on the consumption and perceptions of milk among food shoppers. Three types of milk were included: whole milk, reduced-fat milk and soy milk. The aims of the study were twofold. The first was to investigate and compare perceptions of the three types of milk among the food shopper population. We expected positive perceptions about the taste and nutritional value of milk in general and major differences between reducedfat milk and whole milk on fat-related perceptions. Our second aim was to assess sociodemographic influences on perceptions and type of milk consumed. More positive perceptions of milk in general were expected among women, whereas more negative beliefs about the fat and cholesterol contents of milk were expected among women and higher SES groups. Misperceptions were expected to be most common among lower SES groups. We also hypothesised that, as opposed to whole milk consumption, reduced-fat milk consumption would be more common among women, elderly people and higher SES groups.

\section{Methods}

\section{Subjects}

Questionnaires were administered over four days in a twoweek period (Thursday and Friday in week 1 and Friday and Saturday in week 2) in January and February 2002 to 383 randomly selected shoppers in two shopping centres in Melbourne, Australia, yielding a response rate of $40 \%$. They took between five and ten minutes to complete. Within the sample, subjects were randomly assigned to complete a questionnaire on whole milk, reduced-fat milk or soy milk. Respondents completed the questionnaires immediately after they were selected.

\section{The questionnaire}

A questionnaire was developed to assess sensory and nutritional perceptions of milk. The items were derived from a literature review of consumer attitudes to milk consumption.

The questionnaire was set out in two sections. The first section contained the items concerning sensory and nutritional perceptions of milk. Five-point (strongly disagree, disagree, don't know, agree, strongly agree) response scales were used. In the second section, respondents were asked to indicate their age, sex, household composition, cultural group, education and income, and the usual type of milk consumed: 'whole milk' (3.5 to $4 \%$ fat content), 'reduced-fat' ( 1 to $2 \%$ fat) or 'soy milk' (usually between 3.2 and $3.6 \%$ fat), as well as 'skimmed' milk, which is milk from which all or most of the fat has been removed.

\section{Statistical analysis}

Kruskal-Wallis tests and chi-square analyses were performed to compare the respondents' perceptions of the three types of milk and to examine demographic differences

To reduce the complexity of the data, the item responses were factor-analysed via principal components analysis with varimax rotation. Since separate factor 
analyses on the three types of milk showed approximately the same factor structure, a factor analysis was conducted on the pooled data. Factor scores were saved for further analysis. Cronbach's alphas were calculated to estimate the internal reliability of the factors.

Plotted factor scores showed normality on all factors. Differences and interactions in mean factor scores between types of milk and sociodemographic characteristics were assessed by means of two-way analysis of variance (ANOVA). A conservative alpha level of 0.01 was used in the chi-square cross-tabulations to avoid overdependence on spurious or chance differences in the observed results. Since ANOVA produces scales of higher internal reliability, an alpha level of 0.05 was used in the comparison of factor scores.

Analysis was carried out using SPSS 11.0 for Windows.

\section{Results}

\section{Profile of subjects}

After excluding data from 22 respondents who had not completed the questionnaire satisfactorily (over 10\% of the items missing or no variation in the responses), the sample consisted of 361 respondents who had completed the questionnaire with respect to whole milk, reduced-fat milk or soy milk.

The demographic characteristics of the respondents are described in Table 1 . They are similar to those of previous Australian food shopper surveys ${ }^{26,27}$, although more of the respondents were aged between 45 and 60 years and tertiary-educated than in the general Victoria population ${ }^{28}$.

The three samples did not differ significantly in distribution among the demographic variables.

\section{Results of the factor analysis}

Factor analysis of the individual items revealed eight factors. Table 2 shows the factor structure, factor loadings and percentages of agreement on the individual items. Fig. 1 shows the factor means of the three types of milk.

\section{Differences in factor scores between types of milk}

Dairy milk (whole milk and reduced-fat milk) scored highest on factor 1 (provisionally named Sensory quality), whereas soy milk scored lowest $(F(2,305)=6.62, P=$ $0.002)$. Whole milk received highest agreement on 'tasty' (82\% agreement) and 'feels good in the mouth' (67\%), whereas reduced-fat milk was rated highest on 'necessary in my diet' (73\%). Most of the respondents agreed that dairy milk has good sensory properties but only a minority perceived soy milk in this way.

Most people agreed that milk contains a lot of goodness. Mean factor scores on factor 2 (Goodness) did not differ significantly across milks. Awareness that dairy milk is a good source of calcium was high (86-96\%), whereas soy milk received slightly lower agreement (78\%) and a higher 'don't know' percentage on this item.

Myths about the nutritional content of milk were prevalent among the sample. Notably the misperception that milk contains iron was widespread, with over a third of the respondents agreeing that milk is a good source of iron. However, uncertainty was high on all items. Mean scores on factor 3 ( $M y t h s$ ) were higher for soy milk than for dairy milk $(F(2,305)=14.06, \quad P<0.001)$. Compared with dairy milk, soy milk was rated more highly on 'contains phyto-oestrogens' (35\%) and 'is a good source of fibre' (33\%).

Table 1 Distribution (\%) of demographic characteristics of the respondents $(n=361)$

\begin{tabular}{|c|c|c|c|c|}
\hline Characteristic & Category & Whole milk $(n=127)$ & Reduced-fat milk $(n=117)$ & Soy milk $(n=117)$ \\
\hline \multirow[t]{2}{*}{ Gender } & Male & 44.9 & 31.6 & 35.0 \\
\hline & Female & 55.1 & 68.4 & 65.0 \\
\hline \multirow[t]{5}{*}{ Age (years) } & $18-30$ & 14.2 & 11.1 & 24.8 \\
\hline & $31-40$ & 16.5 & 16.2 & 12.8 \\
\hline & $41-50$ & 11.8 & 20.5 & 15.4 \\
\hline & $51-65$ & 32.3 & 35.9 & 32.5 \\
\hline & Over 65 & 25.2 & 16.2 & 14.5 \\
\hline \multirow[t]{6}{*}{ Education (highest level) } & Never attended school & 0.8 & 0 & 0 \\
\hline & Primary school only & 0.8 & 0.9 & 0.9 \\
\hline & Some high school & 5.6 & 5.2 & 5.1 \\
\hline & High school & 30.2 & 35.3 & 31.6 \\
\hline & Technical or trade certificate & 11.1 & 16.4 & 16.2 \\
\hline & University & 51.6 & 42.2 & 46.2 \\
\hline \multirow[t]{4}{*}{ Annual household income (AUS\$) } & Up to 30000 & 26.6 & 27.6 & 24.0 \\
\hline & $30000-50000$ & 29.4 & 23.5 & 29.0 \\
\hline & $50000-80000$ & 21.1 & 28.6 & 22.0 \\
\hline & More than 80000 & 22.9 & 20.4 & 25.0 \\
\hline \multirow[t]{3}{*}{ Household size } & 1 person & 10.4 & 13.0 & 12.7 \\
\hline & 2 people & 49.6 & 46.3 & 31.8 \\
\hline & 3-7 people & 40.0 & 40.7 & 55.5 \\
\hline \multirow[t]{2}{*}{ Parenthood } & No children under 18 & 65.6 & 69.8 & 61.6 \\
\hline & Children under 18 & 34.4 & 30.2 & 38.4 \\
\hline \multirow[t]{2}{*}{ Ethnic group } & Anglo-Australian & 88.1 & 88.8 & 87.0 \\
\hline & Other & 11.9 & 11.2 & 13.0 \\
\hline
\end{tabular}


Table 2 Factor loadings and percentages of agreement with individual perceptions

\begin{tabular}{|c|c|c|c|c|c|}
\hline & \multirow{2}{*}{$\begin{array}{l}\text { Factor } \\
\text { loading } \ddagger\end{array}$} & \multicolumn{4}{|c|}{ Percentages of agreement $†$} \\
\hline & & Whole milk & Reduced-fat milk & Soy milk & $P$-value§ \\
\hline \multicolumn{6}{|l|}{$\begin{array}{l}\text { Factor 1: Sensory quality } \\
\text { Explained variance: } 10.49 \% \\
\text { Cronbach's alpha: } 0.81\end{array}$} \\
\hline Tasty & 82 & $82(4)$ & $70(8)$ & $49(21)$ & ** \\
\hline Feels good in the mouth & 73 & $67(16)$ & $61(15)$ & $41(28)$ & ** \\
\hline Refreshing & 72 & $65(7)$ & $66(11)$ & $43(24)$ & ** \\
\hline Necessary in my diet & 64 & $61(10)$ & $73(8)$ & $45(26)$ & ** \\
\hline Hard to digest & -55 & $13(15)$ & $9(19)$ & $9(30)$ & NS \\
\hline \multicolumn{6}{|l|}{$\begin{array}{l}\text { Factor 2: Goodness } \\
\text { Explained variance: } 9.51 \% \\
\text { Cronbach's alpha: } 0.78\end{array}$} \\
\hline A good source of vitamins & 70 & $81(17)$ & $74(21)$ & $77(21)$ & NS \\
\hline Safe to drink & 67 & $85(9)$ & $89(8)$ & $82(15)$ & NS \\
\hline A good source of calcium & 58 & $96(2)$ & $86(8)$ & $78(16)$ & ** \\
\hline Acceptable as an adult drink & 53 & $83(10)$ & $87(4)$ & $82(8)$ & NS \\
\hline Natural & 52 & $86(6)$ & $58(21)$ & 78 (13) & ** \\
\hline A good source of protein & 52 & $73(22)$ & $71(22)$ & $71(28)$ & NS \\
\hline \multicolumn{6}{|l|}{$\begin{array}{l}\text { Factor 3: Myths } \\
\text { Explained variance: } 9.36 \% \\
\text { Cronbach's alpha: } 0.75\end{array}$} \\
\hline A good source of fibre & 78 & $18(41)$ & $18(37)$ & $33(53)$ & ** \\
\hline A good source of vitamin C & 75 & $22(47)$ & $22(43)$ & $21(66)$ & ** \\
\hline A good source of iron & 67 & $34(53)$ & $40(47)$ & $35(58)$ & NS \\
\hline A good source of vitamin $D$ & 62 & $25(56)$ & $26(56)$ & $25(68)$ & NS \\
\hline Contains phyto-oestrogens & 55 & $18(73)$ & $13(73)$ & $35(61)$ & ** \\
\hline Contains hormones & 43 & $15(68)$ & $12(61)$ & $11(69)$ & NS \\
\hline \multicolumn{6}{|c|}{$\begin{array}{l}\text { Factor 4: High in energy, fat and cholesterol } \\
\text { Explained variance: } 8.40 \% \\
\text { Cronbach's alpha: } 0.71\end{array}$} \\
\hline High in fat & 84 & $66(17)$ & $13(9)$ & $9(40)$ & ** \\
\hline Low in cholesterol & -71 & $23(34)$ & 76 (15) & $74(24)$ & ** \\
\hline High in calories & 67 & $68(15)$ & 31 (17) & $18(44)$ & ** \\
\hline Creamy & 61 & $87(10)$ & $29(8)$ & $42(26)$ & ** \\
\hline \multicolumn{6}{|l|}{$\begin{array}{l}\text { Factor 5: Not natural } \\
\text { Explained variance: } 6.73 \% \\
\text { Cronbach's alpha: } 0.66\end{array}$} \\
\hline Contains chemicals & 78 & $20(45)$ & $19(52)$ & $15(56)$ & NS \\
\hline Genetically modified & 72 & $17(49)$ & $16(52)$ & $18(50)$ & NS \\
\hline Watery & 50 & $12(9)$ & $43(10)$ & $29(24)$ & ** \\
\hline Natural & -42 & $86(6)$ & $58(21)$ & $78(13)$ & ** \\
\hline \multicolumn{6}{|l|}{$\begin{array}{l}\text { Factor 6: Convenience } \\
\text { Explained variance: } 6.70 \% \\
\text { Cronbach's alpha: } 0.68\end{array}$} \\
\hline Packed in the right size & 76 & $89(7)$ & $85(10)$ & $69(24)$ & ** \\
\hline Convenient to drink & 74 & $93(4)$ & $90(3)$ & $74(11)$ & ** \\
\hline Easily purchased from the shop & 65 & $95(3)$ & $95(4)$ & $88(6)$ & NS \\
\hline \multicolumn{6}{|l|}{$\begin{array}{l}\text { Factor 7: Fashionable } \\
\text { Explained variance: } 4.75 \% \\
\text { Cronbach's alpha: } 0.40\end{array}$} \\
\hline Trendy & 78 & $11(39)$ & $39(29)$ & $36(27)$ & ** \\
\hline A feminine food & 65 & $16(24)$ & 29 (17) & $16(29)$ & NS \\
\hline \multicolumn{6}{|l|}{$\begin{array}{l}\text { Factor 8: Cost } \\
\text { Explained variance: } 4.18 \% \\
\text { Cronbach's alpha: } 0.22\end{array}$} \\
\hline Expensive & 60 & 27 (16) & 33 (19) & $44(22)$ & NS \\
\hline Contains phyto-oestrogens & 54 & $18(73)$ & $13(73)$ & $35(61)$ & $\star *$ \\
\hline
\end{tabular}

† Percentages of responses as 'don't know' are given in parentheses.

$\ddagger$ Factor loadings are in centiles. Only individual items with factor loadings $>0.40$ are mentioned in the table.

$\S P$-value based on chi-square test $(\mathrm{df}=4)$. Significant differences between groups are marked with asterisks: ${ }^{*}, P<0.01 ;{ }^{*}, P<0.001 ; \mathrm{NS}$, not significant. 


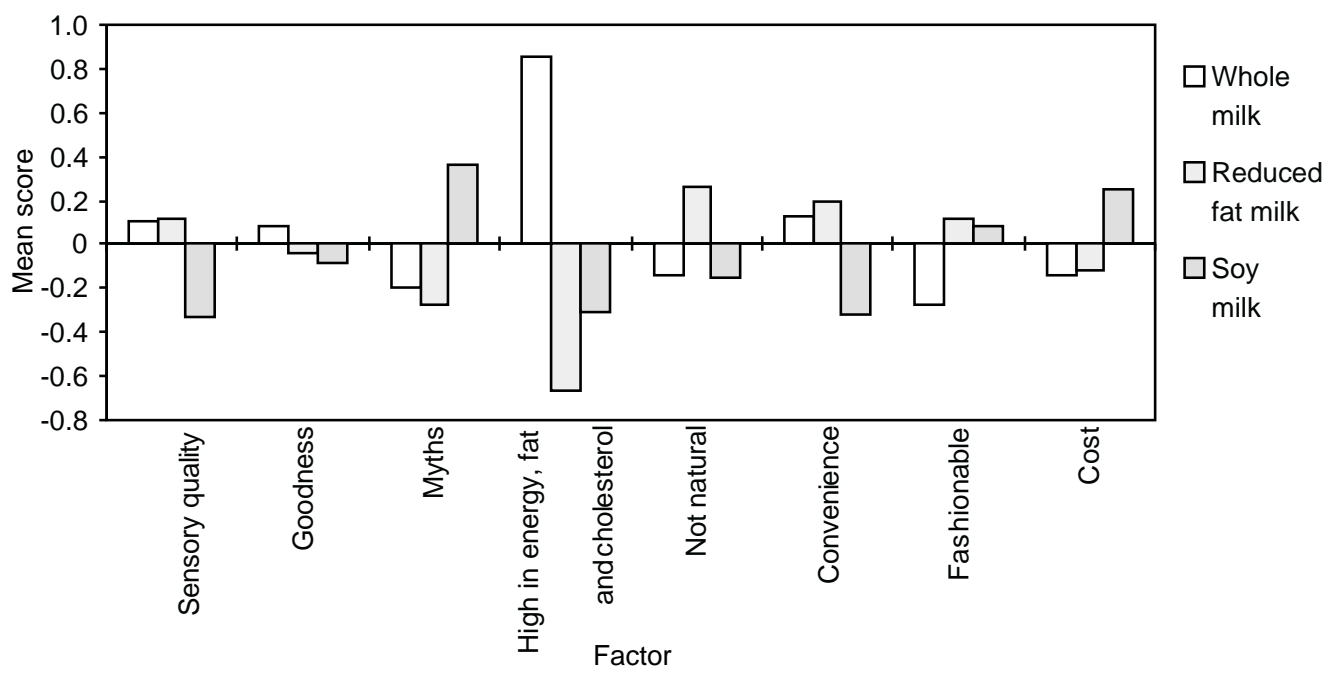

Fig. 1 Mean factor scores

Differences between milks were most striking on factor 4 (High in energy, fat and cholesterol) $(F(2,305)=126.76$, $P<0.001)$. Factor means were highest for whole milk and lowest for reduced-fat milk. Agreement with the individual items confirmed this pattern. A majority of the respondents agreed that whole milk is high in fat, cholesterol and calories, whereas agreement was considerably lower for reduced-fat milk and soy milk. However, levels of uncertainty were considerable.

Mean scores on factor 5 (Not natural) were highest for reduced-fat milk $(F(2,305)=5.55, P=0.004)$ and lowest for whole milk. Differences were most distinct on 'watery' and 'natural', with reduced-fat milk being perceived as most watery (43\% agreement) and least natural (58\%).

Agreement on factor 6 (Convenience) was high across the three types of milk. However, dairy milk scored higher on this factor than soy milk $(F(2,305)=8.58, P<0.001)$. Again, agreement on the individual items confirmed this pattern.

Agreement on factor 7 (Fasbionable) was low across the three types of milk. Mean factor scores were lowest for whole milk $(F(2,305)=5.26, P=0.006)$. Reduced-fat milk was perceived as most trendy (39\% agreement) and feminine (29\%).

Mean scores on factor 8 (provisionally named Cost) were highest for soy milk $(F(2,305)=4.92, P=0.008)$. About a third of the respondents agreed that milk is expensive, with agreement being highest for soy milk.

Differences in factor scores by demographic variables Generally, sociodemographic differences in mean factor scores were few and accounted for only small amounts of variance in the factor scores.

Sex. A significant interaction between sex and type of milk was found on factor 5 (Not natural). Women rated whole milk (mean factor score, 0.01 vs. -0.34) and reduced-fat milk ( 0.40 vs. -0.02$)$ more highly than did men, and rated soy milk lower ( -0.24 vs. 0.12) $(F(2,306)=3.42, P=0.034)$. Women scored higher on factor 6 (Convenience) across the three types of milk $(F(1,306)=5.09, P=0.025)$. Mean factor scores were 0.09 for women and -0.17 for men.

Age. Mean factor scores on factor 6 (Convenience) differed significantly among age groups $(<30$ and 30-50 vs. $>50$ years of age $(F(2,306)=5.10, P=0.007)$. Mean factor scores were lowest among respondents of the 1830 year age group across the three types of milk and were, respectively, $-0.53,0.12$ and 0.10 for the subsequent age groups. Although not significant, respondents over 50 years of age had higher means on factor 4 (High in energy, fat and cholesterol) than younger respondents across all types of milk. Factor means were $-0.09,-0.17$ and 0.09 for the subsequent age groups $(F(2,306)=2.73$, $P=0.067)$.

Education. A significant interaction was found between educational level and type of milk on factor 2 (Goodness) $(F(2,304)=6.17, P=0.002)$. Less-educated respondents (up to high school) had lower factor means on reduced-fat milk ( -0.48 vs. 0.22$)$ and whole milk $(0.02$ vs. 0.10) than tertiary-educated respondents, and higher factor means on soy milk (0.10 vs. -0.20). Less-educated respondents scored higher on factor 5 (Not natural) across all milk types $(F(1,304)=3.96, P=0.047)$. Mean factor scores were 0.12 and -0.11 , respectively.

Parenthood and income. No significant differences in mean factor scores were found across parenthood (children vs. no children under 18 living in the household) and income (annual income less than AUS\$50 000 vs. more than AUS\$50 000).

\section{Differences in factor scores explained by type of milk consumption}

Interactions were found between perceptions of the three types of milk and the usual type of milk consumed 
(skimmed or reduced-fat milk vs. whole milk). On factor 1 (Sensory quality), skimmed and reduced-fat milk drinkers had higher factor means on reduced-fat milk ( 0.47 vs. -0.59), whereas whole milk drinkers scored higher on whole milk (0.65 vs. 0.02$)$ and soy milk ( -0.40 vs. -0.53$)$ $(F(2,255)=16.44, P<0.001)$. On factor 2 (Goodness) drinkers of reduced-fat and skimmed milk had higher factor means on reduced-fat milk (0.22 vs. -0.48) and lower factor means on soy milk $(-0.07$ vs. 0.05$)$. Factor means on whole milk were similar $(-0.01)(F(1,255)=$ 3.73, $P=0.052$ ).

A significant interaction was found between the milk types and soy milk consumption (soy milk drinkers vs. non soy milk drinkers) on factor 1 (Sensory quality) $(F(2,296)=9.04, \quad P<0.001)$. Soy milk drinkers had lower factor scores on whole milk $(-0.07$ vs. 0.16$)$ and higher factor scores on soy milk (0.17 vs. -0.81$)$. Mean factor scores on reduced-fat milk were similar (0.15). Another interaction was found on factor 5 (Not natural) $(F(2,296)=4.28, P=0.015)$. Soy milk drinkers scored higher on whole milk (0.32 vs. -0.26$)$ and reduced-fat milk (0.34 vs. 0.29) and lower on soy milk ( -0.33 vs. 0.025). Third, soy milk drinkers had lower factor means on factor 7 (Fashionable) on all types of milks $(F(1,296)=4.57, P=0.033)$. Mean factor scores were
-0.21 among soy milk drinkers and 0.04 for non soy milk drinkers.

\section{Profile of milk drinkers by type of milk consumed}

Table 3 presents the demographic profiles of the respondents by type of milk consumed. No significant differences in distribution among the demographic variables were found between milk drinkers, except for parenthood $\left(\chi^{2}(3)=11.9, P=0.011\right)$ and age $\left(\chi^{2}(3)=\right.$ 9.76, $P=0.021)$. Whole milk and skimmed milk drinkers were most likely, and reduced-fat and non-milk drinkers were least likely, to have children under 18 living in their household. Whole milk drinkers were younger than respondents who consumed milk with a reduced fat content or no milk.

\section{Profile of soy milk drinkers}

Soy milk drinkers did not differ significantly from non soy milk drinkers in demographic profile. The only significant difference was found in cultural background. Among drinkers of soy milk, there was a higher proportion of people with a non Anglo-Australian background, notably Asian $\left(\chi^{2}(1)=11.64, P=0.001\right)$.

Table 3 Distribution (\%) of demographic characteristics of the respondents by usual type of milk consumption and soy milk consumption

\begin{tabular}{|c|c|c|c|c|c|c|c|}
\hline \multirow[b]{2}{*}{ Characteristic } & \multirow[b]{2}{*}{ Category } & \multicolumn{4}{|c|}{ Usual type of milk consumption* $† \ddagger$} & \multicolumn{2}{|c|}{$\begin{array}{c}\text { Soy milk } \\
\text { consumption†‡ }\end{array}$} \\
\hline & & $\begin{array}{l}\text { Whole milk } \\
\quad(n=94)\end{array}$ & $\begin{array}{l}\text { Reduced-fat milk } \\
\qquad(n=131)\end{array}$ & $\begin{array}{c}\text { Skimmed } \\
\text { milk } \\
(n=70)\end{array}$ & $\begin{array}{l}\text { No milk } \\
(n=46)\end{array}$ & $\begin{array}{l}\text { Soy milk } \\
(n=106)\end{array}$ & $\begin{array}{l}\text { No soy milk } \\
(n=241)\end{array}$ \\
\hline \multirow[t]{2}{*}{ Gender } & Male & 45.7 & 40.5 & 28.6 & 37.0 & 31.1 & 40.7 \\
\hline & Female & 54.3 & 59.5 & 71.4 & 63.0 & 68.9 & 59.3 \\
\hline \multirow[t]{5}{*}{ Age (years) } & $18-30$ & 23.4 & 10.7 & 18.6 & 13.0 & 22.6 & 14.5 \\
\hline & $31-40$ & 19.1 & 16.0 & 11.4 & 10.9 & 15.1 & 15.4 \\
\hline & $41-50$ & 13.8 & 13.7 & 22.9 & 10.9 & 14.2 & 16.6 \\
\hline & $51-65$ & 26.6 & 33.6 & 34.3 & 50.0 & 35.8 & 33.2 \\
\hline & Over 65 & 17.0 & 26.0 & 12.9 & 15.2 & 12.3 & 20.3 \\
\hline \multirow[t]{6}{*}{ Education (highest level) } & Never attended school & 0 & 0 & 0 & 2.2 & 0.9 & 0 \\
\hline & Primary school & 0 & 1.5 & 1.4 & 0 & 0 & 0.8 \\
\hline & Some high school & 5.4 & 5.3 & 4.3 & 4.3 & 7.5 & 4.2 \\
\hline & High school & 30.1 & 32.1 & 34.3 & 32.6 & 31.1 & 33.3 \\
\hline & Technical or trade certificate & 2.6 & 15.3 & 7.1 & 6.5 & 12.3 & 14.6 \\
\hline & University & 41.9 & 45.8 & 52.9 & 54.3 & 48.1 & 47.1 \\
\hline \multirow[t]{4}{*}{ Annual household income (AUS\$) } & Up to 30000 & 28.6 & 24.5 & 25.9 & 19.5 & 24.4 & 26.7 \\
\hline & $30000-50000$ & 29.8 & 26.4 & 25.9 & 26.8 & 30.0 & 27.2 \\
\hline & $50000-80000$ & 26.2 & 23.6 & 19.0 & 29.3 & 25.6 & 23.3 \\
\hline & More than 80000 & 15.5 & 25.5 & 29.3 & 24.4 & 20.0 & 22.8 \\
\hline \multirow[t]{3}{*}{ Household size } & 1 person & 9.1 & 12.8 & 11.8 & 11.4 & 11.0 & 12.2 \\
\hline & 2 people & 39.8 & 49.6 & 35.3 & 40.9 & 33.0 & 45.9 \\
\hline & 3-7 people & 51.1 & 37.6 & 52.9 & 47.7 & 56.0 & 41.9 \\
\hline \multirow[t]{2}{*}{ Parenthood } & No children under 18 & 60.2 & 74.8 & 52.9 & 71.1 & 59.4 & 66.7 \\
\hline & Children under 18 & 39.8 & 25.2 & 47.1 & 28.9 & 40.6 & 33.3 \\
\hline \multirow[t]{2}{*}{ Ethnic group } & Anglo-Australian & 84.6 & 90.8 & 91.4 & 86.7 & 79.0 & 92.0 \\
\hline & Other & 15.4 & 9.2 & 8.6 & 13.3 & 21.0 & 8.0 \\
\hline
\end{tabular}

* For comparative purposes, only respondents who reported consuming one type of milk are included.

† The numbers of respondents answering the three questions at the head of the columns are the minimum numbers who provided information about each demographic characteristic; missing responses reduced the actual sample size from 361 on each characteristic.

$\ddagger$ 'Whole milk' usually has a fat content of 3.5 to $4 \%$, 'reduced-fat milk' from 1 to $2 \%$ fat, 'soy milk' around 3.2 to $3.6 \%$ fat (Sanitarium Nutrition Education Service) and 'skimmed milk' is milk from which all or most of the fat has been removed. 


\section{Discussion}

Four major findings were identified:

1. most people held positive perceptions about milk;

2. major differences in perceptions did exist between milks;

3. misperceptions were prevalent; and

4. only little variation in milk consumption and perceptions could be explained by demographic variables, notably SES.

Generally, people held positive perceptions about milk. The majority of respondents considered milk as having good sensory properties, providing a good source of nutrients, and being a convenient and safe product. Awareness that dairy milk is a good source of calcium was high. This is consistent with previous research ${ }^{6-11}$. Although agreement was slightly lower, the majority of respondents also agreed that soy milk is a good source of calcium. This may pose a threat for public health. If soy milk is considered as a milk substitute calcium intake may be threatened, since the bioavailability of calcium in soy milk is low ${ }^{29}$. To increase awareness of this, health education focusing on adequate dairy consumption, in order to ensure adequate calcium consumption, may be beneficial.

Apart from knowledge about calcium and protein, misperceptions and uncertainty about the nutrient content of milk were prevalent. The most common misperception was that milk is a good source of iron. A similar belief was found in New Zealand by Wham ${ }^{11}$, who found that half (49\%) of the respondents agreed that milk is a good source of iron. She attributed her findings to the intense advertising by the meat industry to raise awareness about iron in food $^{11}$. Furthermore, in the current study, misperceptions were held by about a quarter of the respondents that milk is a good source of fibre and vitamin $\mathrm{C}$. This finding suggests that many people may be largely unaware of the actual nutritional content of milk. Thus, health education might be useful to give people a better understanding of the nutritional properties of milk and the content of marketing campaigns of milk might need some revision.

Taste is an important determinant of food choice ${ }^{14}$ and in this study the majority of the respondents agreed that dairy milk has good sensory properties. Whole milk received highest agreement on taste and mouth feel perceptions, although reduced-fat milk closely followed. This is consistent with previous work showing higher sensory scores on whole milk compared with milks with a reduced fat content ${ }^{17,20}$. The relatively small differences in sensory evaluation between reduced-fat milk and whole milk might be explained by the fact that fat does not affect sensory properties in a linear manner ${ }^{30}$. Frost et al. ${ }^{30}$ found that larger sensory differences were identified between milks with $0.1 \%$ and $1.3 \%$ fat than between milks with $1.3 \%$ and $3.5 \%$ fat. Sensory influences on the type of milk purchasing behaviour may, however, be limited. Nevertheless, it is encouraging for the milk industry that reduced-fat milk had positive sensory acceptance among the majority of respondents. On the other hand, soy milk, which usually has a similar fat content to whole cow's milk, was rated lower in terms of sensory quality and, from the sensory point of view, was not found to be an attractive substitute for milk.

As expected, negative perceptions were most common for whole milk and were mostly related to its perceived fat, cholesterol and energy contents. However, these negative perceptions did not apply to reduced-fat milk. This suggests the milk industry has been successful in providing positive communications about the benefits of low-fat milk. About a third of the respondents agreed that milk is expensive. This may be a barrier to milk consumption, especially among people in lower socioeconomic groups. Glanz et al. ${ }^{31}$ found that, after taste, cost was the most important influence on food choice. Elbon et $a l^{8}$ showed that participants in a community wellness programme in the USA said they would drink more milk if it were less expensive.

\section{Differences in factor scores by demographic variables}

Demographic differences were few and small. Contrary to our expectations, women did not hold more positive perceptions about milk than did men and they were not more concerned about the energy and fat contents. Lesseducated people were less positive about the nutrient content of dairy milk and agreed more that milk is not natural, although, contrary to our expectations, they did not differ in fat-related perceptions. Parents were not more positive about milk than non-parents. Misperceptions and uncertainty about the nutrition content also seemed to be widespread among the sample but again, contrary to expectations, their prevalence did not differ across demographic groups. We have argued elsewhere (unpublished document) that Australians' food perceptions may be little affected by demographics.

\section{Differences in factor scores between consumer groups}

Some differences in mean factor scores were linked to the types of milk consumed. Generally milks that were consumed were viewed more positively than types that were not consumed. The greater preference of drinkers has been observed in other studies ${ }^{13,32}$ and has been attributed to the influence of familiarity in food choice ${ }^{33}$ and to cognitive dissonance ${ }^{32,34}$.

\section{Demographic differences in consumption}

Few demographic differences in type of milk consumption were found. This is consistent with previous Australian studies, which showed few demographic differences in food consumption ${ }^{23,24}$. 


\section{Conclusion}

Although positive perceptions were common, negative perceptions and misperceptions were prevalent. Sociodemographic factors were not shown to be important determinants of type of milk consumption and perceptions and do not justify targeted educational programmes.

\section{Acknowledgements}

Ethics permission was granted by the Human Ethics Committee, Deakin University. The study was funded by a small grant from The School of Health Sciences, Deakin University.

\section{References}

1 Australian Bureau of Statistics (ABS). Apparent Consumption of Foodstuffs and Nutrients, 1993-1994. Canberra: ABS, 1997.

2 Gurr MI. Milk products: contribution to nutrition and health. J. Soc. Dairy Technol. 1992; 45(3): 61-7.

3 Harsha DW, Lin PH, Obarzanek E, Karanja NM, Moore TJ, Caballero B. Dietary Approaches to Stop Hypertension: a summary of study results. J. Am. Diet. Assoc. 1999; 99(Suppl.): S35-9.

4 Miller GD, DiRienzo DD, Reusser ME, McCarron DA. Benefits of dairy product consumption on blood pressure in humans: a summary of the biomedical literature. J. Am. Coll. Nutr. 2000; 19(Suppl. 2): 147S-64S.

5 Massey LK. Dairy food consumption, blood pressure and stroke. J. Nutr. 2001; 131(7): 1875-8.

6 Heywood PF. Food and nutrition knowledge and beliefs of Sydney women. Part 2. Food groups. Food Technol. Aust. 1979; 31: 275-8, 280.

7 Chapman KM, Chan MW, Clark CD. Factors influencing dairy calcium intake in women. J. Am. Coll. Nutr. 1995; 14(4): 336-40.

8 Elbon SM, Johnson MA, Fischer JG. Developing an instrument to measure the influence of knowledge, behaviours, and attitudes on milk consumption patterns in older participants of a community wellness groups: a pilot study. J. Nutr. Elderly 1996; 15(4): 21-37.

9 Harel Z, Riggs S, Vaz R, White L, Menzies G. Adolescents and calcium: what they do and do not know and how much they consume. J. Adolesc. Health 1998; 22: 225-8.

10 Hagy LF, Brochetti D, Duncan SE. Focus groups identified women's perceptions of dairy foods. J. Women Aging 2000; 12(3/4): 99-115.

11 Wham C. Changing New Zealanders' Attitudes to Milk? Adelaide: Department of Public Health, Faculty of Medicine, University of Adelaide, 2000.

12 Australian Bureau of Statistics (ABS). National Nutrition Survey. Nutrient Intakes and Physical Measurements. Australia 1995. Catalogue No. 4805.0. Canberra: ABS, 1998.

13 Tuorila $\mathrm{H}$. Selection of milks with varying fat contents and related overall liking, attitudes, norms and intentions. Appetite 1987; 8: 1-14.

14 Tuorila H, Pangborn RM. Prediction of reported consumption of selected fat containing foods. Appetite 1988; 11: $81-95$.
15 Horwarth CC, Govan CH, Campbell AJ, Busby W, Scott V. Factors influencing milk and milk product consumption in young and elderly women with low calcium intakes. Nutr Res. 1995; 15(12): 1735-45.

16 Saba A, Moneta E, Nardo N, Sinesio F. Attitudes, habit, sensory and liking expectation as determinants of the consumption of milk. Food Qual. Pref. 1998; 9(1/2): 31-41.

17 Brewer JL, Blake AJ, Rankin SA, Douglass LW. Theory of reasoned action predicts milk consumption in women. J. Am. Diet. Assoc. 1999; 99: 39-44.

18 Shepherd R. Belief structure in relation to low fat milk consumption. J. Hum. Nutr. Diet. 1988; 1: 421-8.

19 Cashel KM, Crawford D, Deakin V. Milk choices made by women: what influences them, and does it impact on calcium intake? Public Health Nutr. 2000; 3(4): 403-10.

20 Richardson-Harman NJ, Stevens R, Walker S, Gamble J, Miller M, Wong M, et al. Mapping consumer perceptions of creaminess and liking for liquid dairy products. Food Qual. Pref. 2000; 11(3): 239-46.

21 Wiseman J. Beliefs about food components, foods, fat and heart disease in New Zealand. Br. Food J. 1994; 96(11): 14-9.

22 Rozin P, Fallon AE. Body image, attitudes to weight and misperceptions of figure preferences of the opposite sex: a comparison of males and females in two generations. J. Abnorm. Psychol. 1988; 97: 342-5.

23 Baghurst KI, Record SJ, Baghurst PA, Syrette JA, Crawford D, Worsley A. Sociodemographic determinants in Australia of the intake of food and nutrients implicated in cancer aetiology. Med.J. Aust. 1990; 153: 444-52.

24 Smith AM, Baghurst KI. Public health implications of dietary differences between social status and occupational category groups. J. Epidemiol. Community Health 1992; 46: 409-16.

25 Scragg R, Jackson R, Beaglehole R, Lay-Lee R. The diet of Auckland men and women aged 25-64 years. NZ Med. J. 1991; 104(913): 213-22.

26 Lewis J, Cooper C, van Herwerden E, Crawford D, Watson R. Supermarkets as a setting to promote healthy eating: some lessons learned in Victoria. Health Prom. J. Aust. 2002; in press.

27 Worsley A, Skrzypiec G. Personal predictors of consumers food and health concerns. Asia Pacific J. Clin. Nutr. 1998; 7 : $15-23$.

28 Australian Bureau of Statistics. Census of Population and Housing: Selected Social and Housing Characteristics for Statistical Local Areas: Victoria 1996. Catalogue No. 2015.2 Canberra: Australian Government Publishing Service, 1996.

29 Heaney RP, Dowell MS, Rafferty K, Bierman J. Bioavailability of the calcium in fortified soy imitation milk with some observations on method. Am. J. Clin. Nutr. 2000; 71(5): 1166-9.

30 Frost MB, Dijksterhuis G, Martens M. Sensory perception of fat in milk. Food Qual. Pref. 2000; 12(5-7): 327-36.

31 Glanz K, Basil M, Maibach E. Why Americans eat what they do: taste, nutrition, cost, convenience and weight control concerns as influences on food consumption. J. Am. Diet. Assoc. 1998; 10: 1118-26.

32 Raats MM, Shepherd R. An evaluation of the use and perceived appropriateness of milk using the repertory grid method and the 'item by use' appropriateness method. Food Qual. Pref. 1992; 3: 89-100.

33 Rozin P. Psychobiological and cultural determinants of food choice. In: Silverstone T, ed. Appetite and Food Intake. Berlin: Abakon Verlagsgesellschaft, 1976; 285-312.

34 Festinger L. A Theory of Cognitive Dissonance. Evanston, IL: Row Peterson, 1957. 